\title{
RAD51 Family Gene
}

National Cancer Institute

\section{Source}

National Cancer Institute. RAD51 Family Gene. NCI Thesaurus. Code C20813.

The RAD51 family of related genes, identified in both yeast and humans, encode strandtransfer proteins thought to be involved in recombinational repair of DNA damage and in meiotic recombination. Several members of the mammalian RAD51 gene family have been identified, for example, RAD51A, RAD51B, XRCC3, DMC1, and RAD51C. (From OMIM 602774) 